Original Research Article

\title{
A study on the usage of antimicrobial agents and adverse drug reaction of antimicrobial used in a tertiary care hospital in North East India
}

\author{
Susmita Patowary ${ }^{1 *}$ Mangala Lahkar ${ }^{2}$, Ratan J. Lihite ${ }^{3}$
}

${ }^{1} \mathrm{PhD}$ Scholar, Srimanta Sankaradeva University of Health Sciences, Gauhati Medical College \& Hospital, Guwahati, Assam, India ${ }^{2}$ Department of Pharmacology, Gauhati Medical College and Hospital, Assam, India ${ }^{3}$ Deptment of Pharmacy Practice, National Institute of Pharmaceutical Education and Research (NIPER), Guwahati, Assam, India

Received: 30 March 2018

Revised: 06 April 2018

Accepted: 09 April 2018

\section{*Correspondence to:}

Dr. Susmita Patowary,

Email: suspat@rediffmail.com

Copyright: () the author(s), publisher and licensee Medip Academy. This is an openaccess article distributed under the terms of the Creative Commons Attribution NonCommercial License, which permits unrestricted noncommercial use, distribution, and reproduction in any medium, provided the original work is properly cited.

\begin{abstract}
Background: Irrational use of antimicrobial agents (AMAs) has led to large scale development of drug resistance and adverse drug reactions (ADRs) which has become a growing world -wide concern. The study was conducted to analyze the prescribing pattern of AMAs and to evaluate the reported ADR of the AMAs prescribed.

Methods: A prospective study was conducted by analyzing 900 case sheets receiving AMAs in a tertiary care hospital. The study plan included analysis of average number of AMA prescribed, morbidity profile of patients, types of AMAs used, drug prescribed by generic/brand name, injectable AMA preparations and appropriateness of indication of AMA used. Thirty reported cases of ADR were evaluated for their casualty by Narnajo's scale and severity by Hartwigs scale.

Results: Average number of drugs per prescription was 1.54. Most common morbidity was fever due to various causes. $86.2 \%$ of AMA used was antibiotics. About $72.0 \%$ of AMAs were prescribed by generic name. Percentage of injectable preparation was $85.0 \% .65 .0 \%$ of drugs were prescribed from Essential drug list (EDL). Most offending drug for ADR was fixed drug combination (FDC) $30.0 \%$. Common organ system involved was skin (63.3\%). Most of the ADR were possible $(80.0 \%)$ and mild $(76.6 \%)$ in nature.

Conclusions: Average number of AMAs per prescription was1.54. Percentage of drug prescribed by generic name is encouraging. However use of injectable preparation was very high. Majority of AMAs prescribed were antibiotics which is also very high. Periodic prescription audit will provide feedback to the prescribers and help in reducing the prescribing error and ADR cases.
\end{abstract}

Keywords: Antimicrobial agents, Adverse drug reactions, Generic name, Prescription audit

\section{INTRODUCTION}

Antimicrobial agents are the most commonly prescribed group of drugs but they are one of the most abused drugs as well. It is estimated that $20-50 \%$ of antibiotic used are inappropriate resulting in increased risk of side effects, increase morbidity and mortality, higher cost and increased rate of antimicrobial resistance (AMR) in community pathogens. ${ }^{1}$ Antibiotic resistance has posed a threat to global health especially in developing countries like India where maximum burden of infectious disease prevail. The main contributing factor of these problems are irrational prescription, self medication and over the counter availability of AMAs. ${ }^{2}$ More than $50 \%$ of all 
medicines worldwide are prescribed, dispensed and sold inappropriately and $50 \%$ of patients fail to take them correctly. ${ }^{3}$

Various findings highlighted that there was a high incidence $(>30 \%)$ of irrational prescribing pattern among the prescribers. $^{4,5}$ Non rational prescription usually indicate lack of training on part of prescriber. Training programme of health care professionals as well as periodic audit may improve the rational use of medications and reduce prescribing error. Apart from this drug utilization studies (DUS) can evaluate the rational drug prescribing by evaluating the quality of medical prescription and provide optimum quality of drug therapy.

The empirical use of AMA is the most important factor for increase incidence of ADR and which is very common in clinical practice. ADR reporting is often missed due to lack of awareness and drug safety monitoring. It accounts for $2-6 \%$ of all hospital admissions. ${ }^{6}$ The incidence of ADR varies as low as $0.15 \%$ to as high as $30 \%$ and incidence of fatal ADR is $0.23 \%$ to $0.4 \%{ }^{7,8}$ Drug monitoring is crucial to provide drug safety to the population. It generates valid data on different aspects of ADR and help to evaluate the assessment of causality, severity and preventability. The base of ADR data is spontaneous reporting but awareness about ADR reporting is still very poor amongst the health care professionals hence there is gross under reporting of ADR cases. The present study was under taken to see the usage pattern of AMAs at in patient department (IPD) of Medicine and to evaluate the ADR reported in these cases.

\section{METHODS}

A prospective study was carried out in IPD of Medicine department of Gauhati Medical College Hospital (GMCH) situated in Kamrup district of Guwahati, Assam which caters both rural and urban population of Assam and as well as other North Eastern States of India.

Nine hundred case sheets of IPD were analyzed over a period of one year from August 2014 to July 2015. The sample size of the study was calculated based on admission on emergency day of the six units of the Medicine department. The patients were selected by systematic random sampling to avoid bias. Hundred fifty case sheets from each of the six units were selected.

\section{Inclusion criteria}

- All the patients above 12 years admitted in the IPD of medicine on the emergency day.

- Patients of either sex.

- AMAs prescribed to the patients for treatment as well as for prophylaxis.

\section{Exclusion criteria}

- Incomplete information from the case sheets.

- Cases discharged within 24 hours of admission.
- Patients referred to other departments.

- Patients left against medical advice.

The study based on two types of observations.

- Prescribing pattern of AMAs.

- $\quad$ ADR of AMAs prescribed.

\section{Statistical assessment}

Data were analyzed descriptively and summarized using tables, bar diagrams and pie charts.

\section{RESULTS}

The demographic profile of the patient revealed $52.4 \%(\mathrm{n}=$ $472)$ were male and $47.6 \%(n=428)$ were female. Mean age of the patient was 43.4 years (Table 1$)$.

Table 1: Gender wise distribution of patients.

\begin{tabular}{|lll|}
\hline Sex & Frequency & Percent \\
\hline Male & 472 & 52.4 \\
\hline Female & 428 & 47.6 \\
\hline Total & 900 & 100.0 \\
\hline
\end{tabular}

Highest numbers of patients were prescribed one AMA $(59.9 \%)$ and two AMA in $26.9 \%$ and three and more than three in $13.2 \%$. The average number of AMAs per prescription was 1.54 (Table 2).

Table 2: Average number of AMAs/ prescription.

\begin{tabular}{|lll|}
\hline No. of AMAs & Frequency & $\%$ \\
\hline 1 & 539 & 59.9 \\
\hline 2 & 242 & 26.9 \\
\hline 3 and $>3$ & 119 & 13.2 \\
\hline Total & 900 & 100.0 \\
\hline Mean & 1.54 & \\
\hline SD & 0.81 & \\
\hline
\end{tabular}

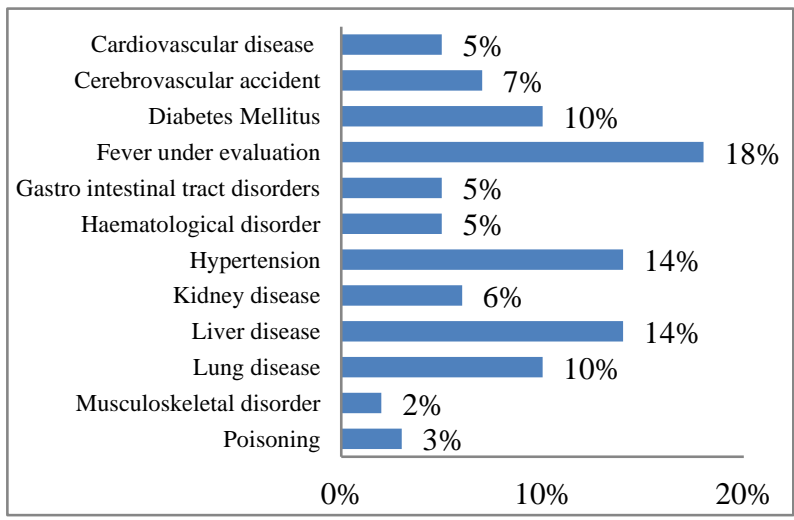

Figure 1: Morbidity profile of patients.

A wide spectrum of morbidity pattern was observed. Maximum cases were fever under evaluation (18.1\%) and 
this is followed by liver disease (14.3\%), hypertension (14.1\%) and lung disease constituted (10.3\%) (Figure 1).

Out of total 1389 AMAs prescribed in 900 patients, 1197 $(86.2 \%)$ were antibiotics and other AMAs comprised of $13.8 \%$. Out of antibiotics cephalosporin topped the list (39.9\%) followed by FDC $(25.7 \%)$. This is followed by quinolones $(4.9 \%)$ and beta lactum $(3.7 \%)$. Other AMAs constituted of metrogyl, artesunate, antifungal, anti retroviral therapy, anti tubercular drugs, anti viral and anti helminthic drugs (Table3).

Table 3: Group of commonly prescribed AMA (Antibiotics and other AMAs).

\begin{tabular}{|lll|}
\hline Group of drug & Frequency & $\%$ \\
\hline Cehpalosporins & 555 & $39.96 \%$ \\
\hline $\begin{array}{l}\text { Fixed drug combination } \\
\text { (FDC) }\end{array}$ & 357 & $25.70 \%$ \\
\hline Quinolones & 69 & $4.97 \%$ \\
\hline $\begin{array}{l}\text { Beta lactums (carbepenems } \\
\text { and monobactums) }\end{array}$ & 52 & $3.74 \%$ \\
\hline Macrolide & 46 & $3.31 \%$ \\
\hline Aminoglycoside & 30 & $2.16 \%$ \\
\hline Oxazolidinone & 27 & $1.94 \%$ \\
\hline Glycopeptides & 20 & $1.44 \%$ \\
\hline Gut antibiotic & 15 & $1.08 \%$ \\
\hline Tetracycline & 9 & $0.65 \%$ \\
\hline Lincosamide & 9 & $0.65 \%$ \\
\hline Sulfonamide & 8 & $0.58 \%$ \\
\hline Other AMAs & 192 & $13.82 \%$ \\
\hline Total & 1389 & \\
\hline
\end{tabular}

Most of the drugs $(72.0 \%)$ were prescribed by generic name and $28.0 \%$ of drugs were prescribed by brand name (Figure 2).

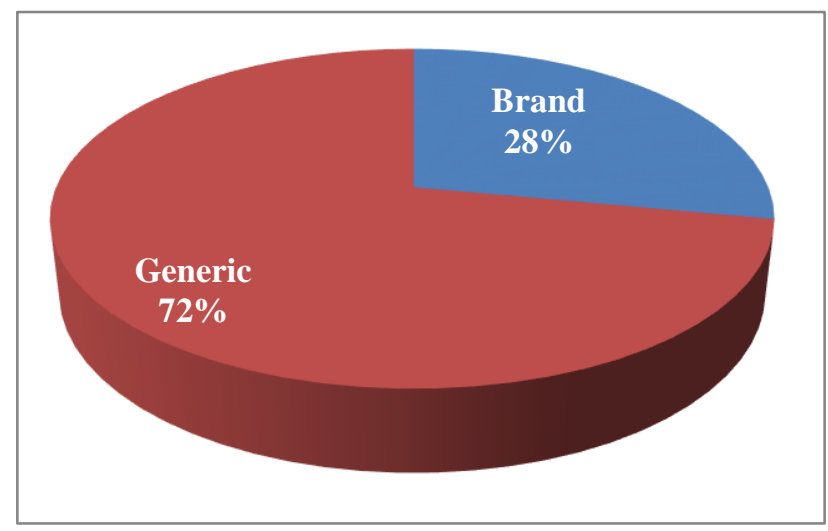

Figure 2: Distribution of group of drugs prescribed by brand/generic name.

Maximum number of patients received AMA by injectable route $(85.0 \%)$ and $15.0 \%$ by oral route (Figure 3 ).

The appropriateness of prescription in regards to indication of AMA use was $74.3 \%$. The duration, dose and frequency were $75.5 \%, 85.2 \%$ and $83.2 \%$ respectively (Table 4).

Table 4: Appropriateness of AMA use.

\begin{tabular}{|ll|l|}
\hline Appropriateness & Frequency & $\%$ \\
\hline Indication & 668 & $74.3 \%$ \\
\hline Duration & 679 & $75.5 \%$ \\
\hline Dose & 766 & $85.2 \%$ \\
\hline Frequency & 748 & $83.2 \%$ \\
\hline
\end{tabular}

In this study the values of prescribing indicators are:

1. Average number of AMAs per prescription - 1.54.

2. Percentage of AMAs prescribed in generic name $>72.0 \%$.

3. Percentage of AMAs prescribed in injectable form $85.0 \%$.

4. Percentage of drug prescribed from EDL (WHO norm) $65.0 \%$

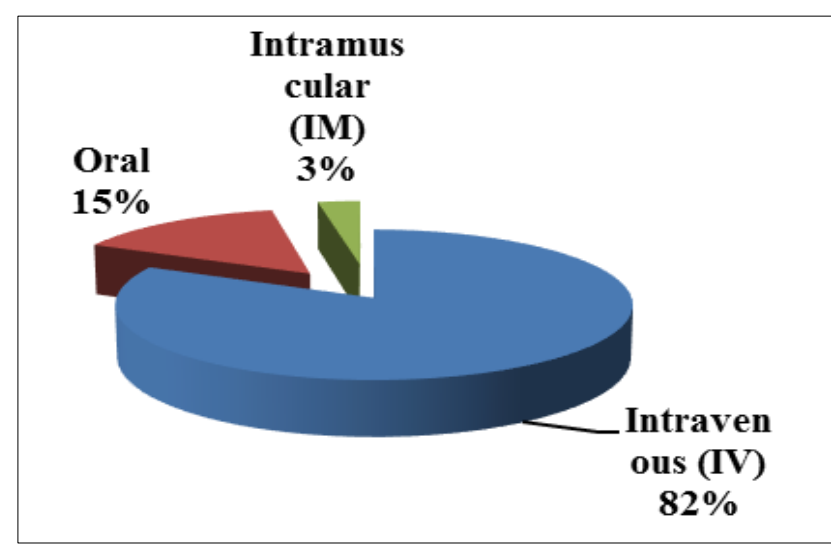

Figure 3: Route of administration.

\section{ADR cases}

The demographic pattern of ADR cases showed that $50.0 \%$ of males and females were in age group of 21-40 years. Sex distribution revealed $66.7 \%(n=20)$ were males and $33.3 \%(n=10)$ were females (Figure 4$)$.

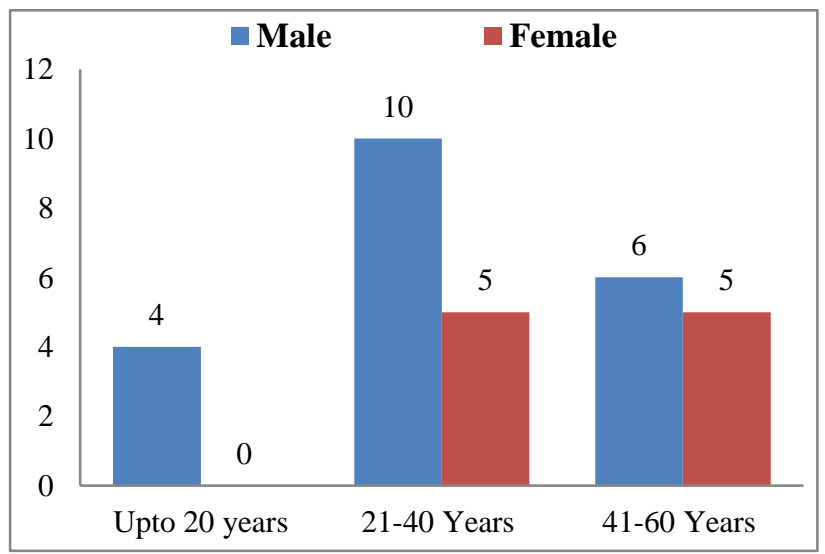

Figure 4: Age and sex distribution of ADR cases. 
The most common therapeutic class of drug causing ADR was FDC $(30.0 \%)$ followed by anti retroviral therapy (ART) (26.7\%) and cephalosporin (16.7\%) (Table 5).

\section{Table 5: Antimicrobial Agents (AMAs) responsible for ADR.}

\begin{tabular}{|lll|}
\hline Groups of drugs & Frequency & $\%$ \\
\hline Cephalosporin & 5 & 16.7 \\
\hline Quinolones & 3 & 10.0 \\
\hline Fixed drug combinations & 9 & 30.0 \\
\hline Anti retroviral therapy & 8 & 26.7 \\
\hline Anti tubercular therapy & 3 & 10.0 \\
\hline Anti fungals & 1 & 3.3 \\
\hline Tetracyclines & 1 & 3.3 \\
\hline
\end{tabular}

Table 6: Organ system involved in ADR cases.

\begin{tabular}{|lll|}
\hline Reaction & Frequency & $\%$ \\
\hline Skin & 19 & 63.3 \\
\hline Gastro intestinal System & 4 & 13.3 \\
\hline Central Nervous System & 2 & 6.7 \\
\hline Genito urinary System & 2 & 6.4 \\
\hline Haematological & 1 & 3.7 \\
\hline Respiratory & 2 & 6.6 \\
\hline Total & 30 & 100.0 \\
\hline
\end{tabular}

Table 7: Clinical manifestation in different organ system in ADR cases.

\begin{tabular}{|ll|}
\hline ADRs & $\begin{array}{l}\text { Number of } \\
\text { ADRs, } \mathbf{N}=\mathbf{3 0}\end{array}$ \\
\hline Skin (19) & 6 \\
\hline Rashes with itching & 4 \\
\hline Itching all over the body & 3 \\
\hline Maculo papular rash & 3 \\
\hline Erythematous itching plaque & 1 \\
\hline Painful purpuric lesion & 1 \\
\hline Itchy scaly papular lesion & 1 \\
\hline Acneform drug eruption & \\
\hline Gastro Intestinal tract (4) & 1 \\
\hline Gastritis and Anorexia & 1 \\
\hline Nausea, Vomiting and Abdominal pain & 1 \\
\hline Dyspepsia & 1 \\
\hline Diarrhoea and anorexia & \\
\hline Central Nervous System (2) & 1 \\
\hline Giddiness and Insomnia & 1 \\
\hline Headache and Vertigo & \\
\hline Musculo Skeletal System (2) & 1 \\
\hline Tendinitis & 1 \\
\hline Generalised weakness & 1 \\
\hline Respiratory System (2) & 1 \\
\hline Difficulty in breathing & \\
\hline Cough and Wheezing & \\
\hline Hematological (1) & 1 \\
\hline Anaemia & \\
\hline
\end{tabular}

The most common organ system involved in ADR was skin $(63.3 \%)$ followed by gastrointestinal system (13.3\%) and central nervous system (CNS) (6.7\%) (Table 6).

The common clinical manifestation of ADR was rash with itching $(n=6)$ and itching all over the body $(n=4)$ followed by maculopapular rash $(n=3)$ and erythematous itching plaque $(n=3)$ (Table 7).

Causality assessment based on Naranjo's scale revealed majority of the suspected ADR cases were probable $80.0 \%$ $(n=24)$, possible $16.7 \%(n=5)$ and only $3.3 \%(n=1)$ were definite.

As per Hartwig's severity assessment scale majority of the ADR were mild $76.6 \%(\mathrm{n}=23), 23.4 \%(\mathrm{n}=6)$ were moderate and none of the cases were severe (Table 8).

Table 8: Distribution of Causality and severity assessment of ADR cases.

\begin{tabular}{|ll|}
\hline Parameter & Number of ADR $(\%) \mathbf{N}=\mathbf{3 0}$ \\
\hline Causality & \\
\hline Doubtful; $\leq 0$ & $0(0.0)$ \\
\hline Possible; $1-4$ & $5(16.7)$ \\
\hline Probable; $5-8$ & $24(80.0)$ \\
\hline Definite; $\geq 9$ & $1(3.3)$ \\
\hline Severity & \\
\hline Mild & $23(76.6)$ \\
\hline Moderate & $7(23.4)$ \\
\hline Severe & $0(0.0)$ \\
\hline
\end{tabular}

\section{DISCUSSION}

In this study $50.2 \%$ of the patients were in the age group of 41-60 years and higher percentage of females was in the lower age group than males. Sex distribution showed male preponderance which was also observed by many authors. ${ }^{9-11}$ The average number of AMA prescribed was low (1.54). Mono therapy of AMA was observed in 59.9\% of cases. Increase in number of drugs per prescription increases the risk of drug interaction various side effects, increase cost and increases the prescribing error. This study tallies with the study of Khan et al., and Ahmed et al. ${ }^{11,12}$

The most common diagnosis was febrile illness (18.0\%) and they are mostly clinically diagnosed either as typhoid or malaria or dengue and other bacterial and viral infections. For these cases AMAs are rather randomly prescribed without waiting for the time consuming laboratory test so that patients are not deprived of the benefits of early treatment. So, culture and sensitivity test were not done in most of the cases in early stage. Higher percentage of liver disease like hepatitis, cirrhosis was mostly due to alcohol abuse which was found to be very common in North East India. 
Amongst the AMA prescribed $86.2 \%$ were antibiotics and cephalosporin topped the list $(39.9 \%)$ followed by FDC $(25.7 \%)$. Cephalosporin was widely prescribed because of its high potent action, availability in various formulations and its broad spectrum activity. Higher percentage of use of cephalosporin was observed in developing countries like India $(82.0 \%)$ and Pakistan $(65.2 \%)$. $^{13,14}$

Indiscriminate use of FDC can lead to various adverse effects, drug interaction. So, it should be avoided as far as possible.

In this study $72.0 \%$ of AMAs were prescribed by generic name. As per WHO recommendation it should be $100 \%$. But $72.0 \%$ is quite high as compared to other studies. Our study tallies with the findings of Admane et al, but this is in contrast to many studies..$^{10,11,15,16}$ This is due to doubt about the efficacy and bioavailability of generic formulations in physicians. Generic drugs are equally effective as brand name drugs and they are less costly.

The reason for higher percentage of patients receiving drugs through IV route is probably due to emergency intervention. When a patient is critically ill, unconscious and diagnosis is not confirmed at the time of admission many drugs are given empirically by IV route. Moreover, most patients received $3^{\text {rd }}$ generation cephalosporin (Inj. Ceftriaxone, Inj. Cefotaxim) which is given by IV route. Over use of injection increases economic burden on patients as well as on health exchequer. This study was in concurrence with other authors. ${ }^{11,17}$ This is in contrast to the finding of other studies. ${ }^{5,15}$

The prescriptions were mostly appropriate as regards dose, duration, frequency and indication.

It is observed that $50.0 \%$ of male and female belonged to the age group of 21-40 years. ADR is reported more in males $(66.7 \%)$ as compared to females (33.3\%). Majority of the ADR were reported in male patients and tallies with the finding of. ${ }^{18-20}$ In this study FDC was the most common offending agent causing ADR which is in conformity with other studies. ${ }^{10,21}$ FDCs are found to be most indiscriminately prescribed AMAs in variety of infection. Incidence of ADR rises with the rise in drug intake. Many epidemiological studies of ADR have shown that number of concurrently used drugs is the most important predictor of these complications. Result of the study has shown FDCs to be maximally contributing for ADR unlike cephalosporin reported in other study. ${ }^{22,23}$ The causality assessment by Naranjo's scale showed that most of the cases categorised as probable $(80.0 \%)$ and $16.7 \%$ were categorised as possible and very small percentage fall in definite category. This is in conformity with similar studies. $^{24-26}$

As per severity assessment scale majority of the cases were mild followed by moderate and none of the reported cases were severe. Jimmy Jose et al found that moderate and mild reactions were more but in contrast to our studies they also found some severe reactions. ${ }^{24}$ The suspected drug was discontinued in $36.7 \%$ of the cases and withdrawn in some cases and treated symptomatically. Most of the patients recovered.

\section{CONCLUSION}

This type of study can provide a framework for continuous prescription audit in health care institutions and help in creating a data base for comparisons of future trends in prescribing pattern of AMAs and help in framing policies towards rational use of drugs. Under reporting of ADR can be reduced by improving spontaneous reporting by sensitising the health care professionals.

Funding: No funding sources

Conflict of interest: None declared

Ethical approval: The study was approved by the Institutional Ethics Committee

\section{REFERENCES}

1. Kotwani A, Holloway K. Trends in antibiotic use among outpatients in New Delhi, India. BMC Infect Dis. 2011;11:99.

2. Hughes JM. Preserving the Lifesaving Power of Antimicrobial Agents. JAMA. 2011;305(10):1027-8.

3. Geetha P, Vijayalakshmi P, Tilak S, Maheswaran A, Narayanan N. Prescription analysis to evaluate the rational use of drugs by using who health care indicators. International journal of Multidisciplinary Research and Development. May 2015;2(5):358-60.

4. Kshirsagar MJ, Langade D, Patil S, Patki PS. Prescribing pattern among Medical practitoners in Pune, India. Bulletin of World Health Organisation. 1998;76(3):271-5.

5. Badar VA, Navale SKB. Study of Prescribing Pattern of Antimicrobial agents in Medicine Intensive Care Unit of a Teaching hospital in Central India. JAPI. April 2012;60:20-3.

6. Pirmohamed M, Breckenridge AM, Kitteringham NR, Park BK. Fortnightly review: adverse drug reactions. BMJ: British Medical Journal. 1998 Apr 25;316(7140):1295-8.

7. Einarson TR. Drug related hospital admission. Ann pharmacother.1993;27 (7-8):832-40.

8. Lazarou J, Pomeranz BH and Corey PN. Incidence of Adverse Drug Reaction in Hospitalized Patients. A Meta analysis of Prospective Studies. Journal of American Medical Association. 1998;279(15):1200-5.

9. Selvaraj R. Prospective assessment of antimicrobial prescribing pattern at a tertiary care hospital. Al Ammen J. Med Sci. 2015;8(4):276-80.

10. Admane PD, Hiware SK, Mahatme MS, Dudhgoankar SD, Deshmukh SN, Mahajan MM. Prescription pattern of antimicrobials in a tertiary care hospital in central India. Int J Pharmaco Res. 2015;5(2):31-4.

11. Khan FA, Singh VK, Sharma S, Singh P. A Prospective Study on the Antimicrobial Usage in the 
Medicine Department of a Tertiary care teaching Hospital. Clin Diagn Res. 2013;7(7):1343-46.

12. Ahmad A, Revanker M, Haque I, Pravina A, Ivan R, Dasari R, et al. Study the prescription pattern of antibiotics in the medicine department in a teaching hospital: a descriptive study. Int J Toxicol Pharmacol Res. 2014;6(2):43-6.

13. Harugeri A, Joseph J, Parthasarathi G, Ramesh M, Guido S. Prescribing patterns and predictors of highlevel polypharmacy in the elderly population: A prospective surveillance study from two teaching hospitals in India. Am J Geriatr Pharmacother. 2010;8(3):271-80.

14. Karim A, Atif MA, Irshad M, Khalid F. Survey of antibiotic utilization at Sheikh Zayed Hospital. J Shiekh Zayed Med College Rahim Yar Khan. 2011;2(2):168-70.

15. Pandiamunian J, Somasundaram G. A study on prescribing pattern of anti microbial agents in the medical intensive care unit of a tertiary care hospital in Puducherry Union Territory, South India. Int J Pharm Sci. 2014;6(3):235-8.

16. Jimoh AO, Etuk EU, Sani Z, Shuaibu HA. The pattern of antibiotic use in a family medicine department of a tertiary hospital in Sokoto, North Western Nigeria. Journal of clinical and diagnostic research. 2011;5(3):566-9.

17. McGowan JE Jr. Economic impact of antimicrobial resistance. Emerg Infect Dis. 2001;7(2):286-92.

18. Shrivastava M, Uchit G, Chakravarti A, Joshi G, Mahatme M, Chaudhari H. Adverse drug reactions reported in Indira Gandhi government medical college and hospital, Nagpur. J Assoc Physicians India. 2011 May;59:296-9.

19. Dhar K, Sinha A, Gaur P, Goel R, Chopra VS, Bajaj U. Pattern of adverse drug reactions to antibiotics commonly prescribed in department of medicine and pediatrics in a tertiary care teaching hospital, Ghaziabad. J App Pharm Sci. 2015;5(4):78-82.

20. Shamna M, Dilip C, Ajmal M, Mohan PL, Shinu C, Jafer CP, et al. A prospective study on Adverse Drug Reactions of antibiotics in a tertiary care hospital. Saudi pharmaceutical journal. 2014 Sep 1;22(4):3038.

21. Halkai K, Deshmukh SK, Rao YV. An Evaluation of Adverse Drug Reactions at ADR Monitoring Centre in Tertiary Care Hospital. International Journal of Therapeutic Applications. 2016;32:86-9.

22. Steinman MA, Rosenthal GE, Landefeld CS, Bertenthal, Daniel MPH, Sen Saunak. Conflicts and concordance between measures of medication and prescribing quality. Med Care. 2007;45(1):95-9.

23. Singh H, Dulhani N, Kumar B, Singh P, Tewari P, Nayak K. A pharmacovigilance study in medicine department of tertiary care hospital in Chhattisgarh (Jagdalpur), India. J Young Pharm. 2010;2(1):95-100.

24. Jose J, Rao PGM, Jimmy, Beena. Adverse drug reactions to fluoroquinolone antibiotics - Analysis of reports received in a tertiary care hospital. Int J Risk Saf Med. 2008;20:169-80.

25. Stavreva, G, Pendicheva, D, Pandurska A, Marev R. Detection of adverse drug reactions to antimicrobial drugs in hospitalized patient. Trakia J Sci. 2008;6(1):7-9.

26. Priyadharsini R, Surendiran A, Adithan C, Sreenivasan S, Sahoo, Kumar F. A study on adverse drug reactions in pediatric patients. J Pharmacol Pharmacother. 2011;2(4):272-80.

Cite this article as: Patowary S, Lahkar M, Lihite RJ. A study on the usage of antimicrobial agents and adverse drug reaction of antimicrobial used in a tertiary care hospital in North East India. Int J Basic Clin Pharmacol 2018;7:833-8. 